\title{
Thromboembolism and bleeding in patients with atrial fibrillation and stage 4 chronic kidney disease: impact of biomarkers
}

\author{
Paweł T Matusik1,2, Wiktor J Leśniak³, Zbigniew Heleniak4, Anetta Undas5,6 \\ 'Department of Electrocardiology, Institute of Cardiology, Jagiellonian University Medical College, Kraków, Poland \\ 2Department of Electrocardiology, The John Paul II Hospital, Kraków, Poland \\ ${ }^{3}$ Faculty of Medicine, Jagiellonian University Medical College, Kraków, Poland \\ ${ }^{4}$ Department of Nephrology, Transplantology and Internal Medicine, Medical University of Gdansk, Gdańsk, Poland \\ ${ }^{5}$ Department of Experimental Cardiac Surgery, Anesthesiology and Cardiology, Institute of Cardiology, Jagiellonian University Medical College, Kraków, Poland \\ ${ }^{6}$ Krakow Centre for Medical Research and Technologies, The John Paul II Hospital, Kraków, Poland
}

\section{Editorial}

by Krittayaphong

see p. 1058

\section{Correspondence to: Paweł T Matusik, MD, PhD, Department of Electrocardiology, Institute of Cardiology, Jagiellonian University Medical College, Prądnicka 80, 31-202 Kraków, Poland, phone: +48 126142277 e-mail: pawel.matusik@uj.edu.pl Copyright by the Author(s), 2021 \\ Kardiol Pol. 2021: 79 (10): 1086-1092; DOl: 10.33963/KP.a2021.0088 Received: July 20, 2021 Revision accepted: August 9, 2021 Published online: August 9, 2021}

\section{A B S TR A C T}

Background: Chronic kidney disease (CKD) is considered a risk factor for thromboembolic and bleeding events in patients with atrial fibrillation (AF).

Aims: We sought to assess predictors of clinical outcomes among AF patients with advanced CKD.

Methods: In a prospective cohort study, we enrolled $180 \mathrm{AF}$ patients with stage 4 CKD, defined as estimated glomerular filtration rate of $15-29 \mathrm{ml} / \mathrm{min} / 1.73 \mathrm{~m}^{2}$, on vitamin $\mathrm{K}$ antagonists $(\mathrm{n}=90)$, and non-vitamin $\mathrm{K}$ antagonists oral anticoagulants $(n=90)$. We assessed biomarkers, including growth differentiation factor-15, cystatin $\mathrm{C}$, and high-sensitivity cardiac troponin $\mathrm{T}$, and prothrombotic state parameters, including plasma fibrin clot permeability $\left(\mathrm{K}_{\mathrm{s}}\right)$.

Results: The median age of the patients was 71.0 (64.0-75.0) years (men 65.0\%). The median estimated glomerular filtration rate was $24.0(21.0-25.0) \mathrm{ml} / \mathrm{min} / 1.73 \mathrm{~m}^{2}$ while the median $\mathrm{CHA}_{2} \mathrm{DS}_{2}-\mathrm{VASc}$ score was $3.0(2.0-4.0)$. Age (hazard ratio $[\mathrm{HR}], 1.11 ; 95 \%$ confidence interval $[\mathrm{Cl}], 1.02-1.20)$ and decreased $K_{s}(H R, 0.55 ; 95 \%$ Cl, 0.34-0.90) were associated with thromboembolic events ( $n=18 ; 4.7 \%$ per year). Previous bleeding ( $\mathrm{HR}, 3.21 ; 95 \% \mathrm{Cl}, 1.22-8.45)$, growth differentiation factor-15 (HR, 1.48; $95 \% \mathrm{Cl}$, 1.29-1.69), cystatin C (HR, 9.24; 95\% Cl, 2.15-39.67), and high-sensitivity cardiac troponin T (HR, 1.30; $95 \% \mathrm{Cl}, 1.14-1.48)$ were independent predictors of major or clinically relevant non-major bleeding $(n=27 ; 7.1 \%$ per year). After adjustment for age and comorbidities, only cystatin $\mathrm{C}(\mathrm{HR}, 3.95 ; 95 \% \mathrm{Cl}$, $1.08-14.37$ ) predicted mortality ( $n=25 ; 6.5 \%$ per year).

Conclusions: Novel biomarkers might be useful in risk stratification of thromboembolic and bleeding events in AF patients with stage 4 CKD receiving oral anticoagulants.

Key words: atrial fibrillation, biomarkers, bleeding, chronic kidney disease, stroke

Kardiol Pol 2021; 79, 10: 1086-1092

\section{INTRODUCTION}

Atrial fibrillation (AF) constitutes the most prevalent type of sustained cardiac arrhythmia in adults and increases the risk of ischemic stroke, systemic thromboembolism, left ventricular dysfunction, heart failure, vascular dementia, and mortality $[1,2]$. Chronic kidney disease (CKD) is as- sociated with incident $A F$, which increases rates of stroke and death in patients with CKD [3]. Moreover, AF itself is associated with a higher risk of developing or progression of CKD [4]. Patients with concomitant stage 4 CKD, defined as estimated glomerular filtration rate (eGFR) of $15-29 \mathrm{ml} / \mathrm{min} / 1.73 \mathrm{~m}^{2}$, are at increased risk for thrombo- 
WHAT'S NEW?

The present cohort study identifies novel biomarkers which might predict clinical outcomes in anticoagulated patients with atrial fibrillation and stage 4 chronic kidney disease. Age and denser fibrin clots have been found to be associated with thromboembolic events. Previous bleeding, growth differentiation factor-15, cystatin C, and high-sensitivity cardiac troponin T can predict major or clinically relevant non-major bleedings. In these high-risk patients on oral anticoagulation, cystatin $\mathrm{C}$ is independently associated with mortality.

embolic events (TE) compared to those with better kidney function [5]. However, CKD has not been included in the CHADS-65 or $\mathrm{CHA}_{2} \mathrm{DS}_{2}$-VASc score [6].

Vitamin $\mathrm{K}$ antagonists (VKA) and non-VKA oral anticoagulants (NOACs) are effective in the prevention of cerebrovascular ischemic events in AF patients $[7,8]$. The latter are currently the preferred therapeutic option also in patients with CKD, except for those with creatinine clearance below $15 \mathrm{ml} / \mathrm{min}$ [9]. In AF patients with creatinine clearance of $15-29 \mathrm{ml} / \mathrm{min}$, the recommended daily doses are $15 \mathrm{mg}$ daily for rivaroxaban and $2.5 \mathrm{mg}$ twice a day for apixaban, but in the US, dabigatran $75 \mathrm{mg}$ twice a day is another option $[9,10]$. In this patient group, education is of key importance for anticoagulation safety [11].

$\mathrm{N}$-terminal pro-B-type natriuretic peptide (NT-proBNP) and high-sensitivity cardiac troponin have been identified as independent predictors of TE in AF [12]. It has been shown that the combination of the two biomarkers with basic clinical data may improve stroke risk assessment in AF [13] while mortality in AF can be predicted by combining age and heart failure status with growth differentiation factor-15 (GDF-15), NT-proBNP, and high-sensitivity cardiac troponin T (cTnT-hs) [14]. Cystatin C, a glomerular filtration marker associated with cardiovascular diseases, has been recently demonstrated as a predictor of acute ischemic stroke [15]. Renal function may affect circulating levels of biomarkers [16]. Landmark AF trials, which assessed biomarkers, generally excluded subjects with creatinine clearance below $30 \mathrm{ml} / \mathrm{min}[9,17]$. Therefore, little is known about the prognostic value of biomarkers in this subset of AF patients with CKD. It has been suggested that increased density of fibrin networks and prolonged clot lysis can predict TE and major bleeding events in anticoagulated AF patients [18-20]. Although we have recently shown that stage 4 CKD in AF patients is associated with unfavorable fibrin clot phenotype [5], its predictive value in terms of clinical outcomes, in this subgroup of patients, has not been evaluated yet.

We tested the hypothesis that GDF-15, cTnT-hs, and cystatin $\mathrm{C}$, along with prothrombotic variables can predict complications of AF in patients with stage 4 CKD during anticoagulant therapy.

\section{METHODS}

We included 180 adults with a history of AF and stage $4 \mathrm{CKD}$, defined as 2 or more eGFR values in the range of $15-29 \mathrm{ml} / \mathrm{min} / 1.73 \mathrm{~m}^{2}$ assessed using the CKD Epidemiology Collaboration (CKD-EPI) formula [10], enrolled in Kraków, Poland, between January 2014 and October 2017, with complete clinical and laboratory data. The inclusion and exclusion criteria were presented previously [10]. Briefly, the exclusion criteria were acute infection, liver injury, acute coronary syndrome in the preceding 12 months, and known active malignancy. The study was approved by the Bioethical Committee of the Jagiellonian University. All patients provided written informed consent.

Using a standardized questionnaire, we collected data on demographics, cardiovascular risk factors, comorbidities, and medications used. Definitions of risk factors and comorbidities were described previously [10].

\section{Laboratory studies}

Fasting venous blood samples were taken from the antecubital vein from the patients off anticoagulation. The patients on VKA were switched to a low-molecular-weight heparin, and blood samples were collected at least 12 hours after the last heparin injection. In the group of patients receiving rivaroxaban, or apixaban, blood samples were taken at least $24 \mathrm{~h}$ after the last dose. Routine laboratory tests were performed by standard laboratory techniques. The Clauss method was used to determine fibrinogen. Plasminogen activator inhibitor-1 (PAI-1) and thrombin-activatable fibrinolysis inhibitor were assessed by ELISAs (American Diagnostica, Stamford, CT, USA and Chromogenix, Lexington, MA, USA, respectively) [21]. Biomarkers such as GDF-15 and NT-proBNP were measured using electrochemiluminescence immunoassays (Roche Diagnostics, Mannheim, Germany) [21]. Endogenous thrombin potential (ETP) was quantified using calibrated automated thrombography, as previously described [21]. Fibrin clot permeability $\left(\mathrm{K}_{\mathrm{s}}\right)$, reflecting the average size of fibrin clot network pores, was calculated using the following equation: $\mathrm{K}_{\mathrm{s}}=\mathrm{Q} \times \eta \times \mathrm{L} / \mathrm{t} \times \mathrm{A} \times \Delta \mathrm{p}$, where $Q$ indicates the flow rate in percolating time $(t), \eta$ reflects the viscosity of liquid in the poise, $L$ is the length of a fibrin gel, $\Delta \mathrm{p}$ is a differential pressure in dyne $/ \mathrm{cm}^{2}$, while $A$ indicates the cross-sectional area in $\mathrm{cm}^{2}$. Clot lysis time (CLT), indicating fibrin clot susceptibility to lysis was assessed as described [21]. CLT was measured from the midpoint of the clear-to-maximum-turbid transition to the midpoint of the maximum-turbid-to-clear transition.

\section{Follow-up}

The participants were followed up via phone calls at least twice a year or through clinic visits till January 2019. The occurrence of stroke/transient ischemic attack was the primary study outcome that was diagnosed based on 
Table 1. Baseline patient characteristics in relation to the presence or absence of thromboembolic or bleeding events in the follow-up

\begin{tabular}{|c|c|c|c|c|c|c|c|}
\hline Variable & $\begin{array}{l}\text { Whole group } \\
\qquad(n=180)\end{array}$ & $\begin{array}{c}\text { No TE } \\
(n=162)\end{array}$ & $\begin{array}{c}\text { TE } \\
(n=18)\end{array}$ & $\boldsymbol{P}$-value & $\begin{array}{l}\text { No bleeding } \\
(n=153)\end{array}$ & $\begin{array}{l}\text { Bleeding } \\
(n=27)\end{array}$ & $P$-value \\
\hline \multicolumn{8}{|l|}{ Demographics } \\
\hline Age, years & $71.0(64.0-75.0)$ & $70.0(64.0-75.0)$ & $73.0(69.0-78.3)$ & 0.07 & $71.0(64.0-75.0)$ & $71.0(66.0-76.0)$ & 0.50 \\
\hline Male sex, n (\%) & $117(65.0)$ & $106(65.4)$ & $11(61.1)$ & 0.72 & $102(66.7)$ & $15(55.6)$ & 0.26 \\
\hline $\mathrm{BMI}, \mathrm{kg} / \mathrm{m}^{2}$ & $27.8(25.6-31.6)$ & $27.8(25.6-31.5)$ & $27.0(25.3-32.7)$ & 0.88 & $28.1(25.6-32.2)$ & $26.6(25.3-29.5)$ & 0.08 \\
\hline Persistent AF, n (\%) & $84(46.7)$ & $76(46.9)$ & $8(44.4)$ & 0.84 & $73(47.7)$ & $11(40.7)$ & 0.50 \\
\hline Permanent AF, n (\%) & $96(53.3)$ & $86(53.1)$ & $10(55.6)$ & & $80(52.3)$ & $16(59.3)$ & \\
\hline $\mathrm{CHA}_{2} \mathrm{DS}_{2}$-VASc score & $3.0(2.0-4.0)$ & $3.0(2.0-4.0)$ & $3.0(3.0-4.0)$ & 0.25 & $3.0(2.0-4.0)$ & $3.0(2.0-4.0)$ & 0.76 \\
\hline Past bleeding, n (\%) & $11(6.1)$ & $11(6.8)$ & $0(0.0)$ & 0.61 & $5(3.3)$ & $6(22.2)$ & 0.002 \\
\hline \multicolumn{8}{|c|}{ Comorbidities and CVD risk factors, $\mathrm{n}(\%)$} \\
\hline Hypertension & $105(58.3)$ & $96(59.3)$ & $9(50.0)$ & 0.45 & $89(58.2)$ & $16(59.3)$ & 0.92 \\
\hline Diabetes mellitus & $64(35.6)$ & $56(34.6)$ & $8(44.4)$ & 0.41 & $55(35.9)$ & $9(33.3)$ & 0.79 \\
\hline Dyslipidemia & $134(74.4)$ & $122(75.3)$ & $12(66.7)$ & 0.41 & $114(74.5)$ & $20(74.1)$ & 0.96 \\
\hline Smoking history & $27(15.0)$ & $24(14.8)$ & $3(16.7)$ & 0.74 & $22(14.4)$ & $5(18.5)$ & 0.56 \\
\hline CAD & $83(46.1)$ & $73(45.1)$ & $10(55.6)$ & 0.40 & $72(47.1)$ & $11(40.7)$ & 0.54 \\
\hline Previous Ml & $39(21.7)$ & $37(22.8)$ & $2(11.1)$ & 0.37 & $32(20.9)$ & $7(25.9)$ & 0.56 \\
\hline Heart failure & $44(24.4)$ & $40(24.7)$ & $4(22.2)$ & 1.0 & $38(24.8)$ & $6(22.2)$ & 0.77 \\
\hline COPD & $24(13.3)$ & $21(13.0)$ & $3(16.7)$ & 0.71 & $22(14.4)$ & $2(7.4)$ & 0.54 \\
\hline \multicolumn{8}{|l|}{ Medications, n (\%) } \\
\hline$\beta$-blocker & $152(84.4)$ & $139(85.8)$ & $13(72.2)$ & 0.17 & $133(86.9)$ & $19(70.4)$ & 0.04 \\
\hline ACE-I & $119(66.1)$ & $106(65.4)$ & $13(72.2)$ & 0.56 & $103(67.3)$ & $16(59.3)$ & 0.42 \\
\hline ARB & $22(12.2)$ & $20(12.3)$ & $2(11.1)$ & 1.0 & $20(13.1)$ & $2(7.4)$ & 0.54 \\
\hline $\mathrm{CCB}$ & $38(21.1)$ & $32(19.8)$ & $6(33.3)$ & 0.22 & $32(20.9)$ & $6(22.2)$ & 0.88 \\
\hline Aspirin & $73(40.6)$ & $64(39.5)$ & $9(50.0)$ & 0.39 & $61(39.9)$ & $12(44.4)$ & 0.66 \\
\hline Clopidogrel & $8(4.4)$ & $7(4.3)$ & $1(5.6)$ & 0.58 & $6(3.9)$ & $2(7.4)$ & 0.34 \\
\hline Statin & $125(69.4)$ & $115(71.0)$ & $10(55.6)$ & 0.18 & $108(70.6)$ & $17(63.0)$ & 0.43 \\
\hline Digoxin & 34 (18.9) & $32(19.8)$ & $2(11.1)$ & 0.53 & $29(19.0)$ & $5(18.5)$ & 0.96 \\
\hline Amiodarone & $28(15.6)$ & $25(15.4)$ & $3(16.7)$ & 1.0 & $22(14.4)$ & $6(22.2)$ & 0.39 \\
\hline \multicolumn{8}{|c|}{ Anticoagulants used during follow-up, $n$ (\%) } \\
\hline NOAC & $90(50.0)$ & $79(48.8)$ & $11(61.1)$ & 0.32 & $76(49.7)$ & $14(51.9)$ & 0.84 \\
\hline Vitamin $\mathrm{K}$ antagonist & $90(50.0)$ & $83(51.2)$ & $7(38.9)$ & & $77(50.3)$ & $13(48.1)$ & \\
\hline
\end{tabular}

Data are presented as median (IQR) or number (\%)

Abbreviations: $A C E-I$, angiotensin-converting enzyme inhibitor; $A F$, atrial fibrillation; $A R B$, angiotensin II receptor blocker; $B M I$, body mass index; $C A D$, coronary artery disease; CCB, calcium channel blocker; COPD, chronic obstructive pulmonary disease; CVD, cardiovascular disease; Ml, myocardial infarction; $\mathrm{n}$, number; NOAC, non-vitamin K antagonist oral anticoagulant; TE, thromboembolism

the World Health Organization criteria. Major bleeding or clinically relevant non-major bleeding (CRNMB) were the secondary outcomes, which were defined as described previously $[22,23]$. Deaths were also recorded.

\section{Statistical analysis}

Continuous variables are shown as the means (standard deviations) or medians (interquartile ranges) and were compared using the Student's or Welch's t-test or Mann-Whitney $\mathrm{U}$ test, as appropriate. $P$-values $<0.05$ were considered statistically significant. Statistical analyses were performed with the use of IBM SPSS Statistics for Windows (version 26, IBM Corp., Armonk, NY, USA) or STATISTICA (version 13.3, TIBCO Software Inc., Palo Alto, CA, USA), for Youden indexes and areas under the curves (AUC) calculations. For details see supplemental material.

\section{RESULTS}

\section{Patients}

A total of 180 AF patients (men 65\%, median age; 71.0 [64.0-75.0] years) with stage 4 CKD (median eGFR,
24.0; interquartile range $21.0-25.0 \mathrm{ml} / \mathrm{min} / 1.73 \mathrm{~m}^{2}$ ) and a median $\mathrm{CHA}_{2} \mathrm{DS}_{2}$-VASc score of 3.0 (2.0-4.0) were studied (Table 1). The majority of the patients had hypertension, while diabetes mellitus was diagnosed in $35.6 \%$ of them, which were the main causes of CKD in this cohort (Table 1). None of the patients had proteinuria above $1 \mathrm{~g}$ per day. No lupus nephritis cases were included. Half of the patients were treated with VKA, while the other half was on apixaban or rivaroxaban (Table 1). Among the patients on VKA, the mean time in the therapeutic range was $65.6(16.5) \%$ while the percentage of patients with time in the therapeutic range $\geq 70.0 \%$ was $42.2 \%(n=38)$.

Age, sex, and body mass index (BMI) were not associated with NT-proBNP, GDF-15, or cTnT-hs. An inverse association was observed between $B M I$ and cystatin $C(R=-0.16$; $P=0.04)$. The $\mathrm{CHA}_{2} \mathrm{DS}_{2}$-VASc score did not correlate with any of the four biomarkers. GDF-15 was positively associated with cTnT-hs $(\mathrm{R}=0.35 ; P<0.0001)$ while other correlations between the major studied biomarkers were generally weaker or absent. Analysis of the four biomarkers in relation to the prothrombotic markers did not reveal potent associations among them (R between -0.23 to 0.23 ) in stage 4 CKD. 
Table 2. Laboratory and hemostatic parameters in relation to the presence or absence of thromboembolic or bleeding events in the follow-up

\begin{tabular}{|c|c|c|c|c|c|c|c|}
\hline Variable & $\begin{array}{l}\text { Whole group } \\
\qquad(n=180)\end{array}$ & $\begin{array}{c}\text { No TE } \\
(n=162)\end{array}$ & $\begin{array}{c}\text { TE } \\
(n=18)\end{array}$ & $P$-value & $\begin{array}{l}\text { No bleeding } \\
(n=153)\end{array}$ & $\begin{array}{l}\text { Bleeding } \\
(n=27)\end{array}$ & $P$-value \\
\hline eGFR, $\mathrm{ml} / \mathrm{min} / 1.73 \mathrm{~m}^{2}$ & $24.0(21.0-25.0)$ & $24.0(21.0-25.0)$ & $24.0(21.0-26.0)$ & 0.54 & $24.0(21.0-25.0)$ & $23.0(22.0-26.0)$ & 0.60 \\
\hline Hemoglobin, g/dl & $12.2(1.3)$ & $12.2(1.3)$ & $12.2(1.7)$ & 0.99 & $12.2(1.3)$ & $12.2(1.3)$ & 0.84 \\
\hline Platelets, $\times 1000 / \mu \mathrm{l}$ & $\begin{array}{c}217.5 \\
(189.0-288.0)\end{array}$ & $\begin{array}{c}217.5 \\
(189.0-280.0)\end{array}$ & $\begin{array}{c}216.5 \\
(184.8-328.0)\end{array}$ & 0.72 & $\begin{array}{c}221.0 \\
(189.0-293.0)\end{array}$ & $\begin{array}{c}209.0(184.0- \\
254.0)\end{array}$ & 0.18 \\
\hline Cystatin C, mg/l & $1.2(1.0-1.3)$ & $1.2(1.0-1.3)$ & $1.2(1.1-1.2)$ & 0.80 & $1.1(1.0-1.2)$ & $1.2(1.2-1.3)$ & $<0.0001$ \\
\hline hs-CRP, mg/l & $2.8(1.5-4.1)$ & $2.8(1.5-4.0)$ & $2.9(1.8-5.7)$ & 0.30 & $3.0(1.5-4.1)$ & $2.6(1.3-4.0)$ & 0.46 \\
\hline GDF-15, pg/ml & $\begin{array}{c}1729.0 \\
(1564.5-2051.8)\end{array}$ & $\begin{array}{c}1734.0 \\
(1568.0-2085.0)\end{array}$ & $\begin{array}{c}1630.0 \\
(1472.0-1887.5)\end{array}$ & 0.18 & $\begin{array}{c}1675.0 \\
(1543.0-1862.0)\end{array}$ & $\begin{array}{c}2319.0 \\
(2165.0-2498.0)\end{array}$ & $<0.0001$ \\
\hline NT-proBNP, pg/ml & $\begin{array}{c}684.0 \\
(399.0-1092.5)\end{array}$ & $\begin{array}{c}674.5 \\
(399.0-1073.5)\end{array}$ & $\begin{array}{c}850.5 \\
(127.0-1149.5)\end{array}$ & 0.74 & $\begin{array}{c}665.0 \\
(408.5-1054.5)\end{array}$ & $\begin{array}{c}836.0 \\
(265.0-1166.0)\end{array}$ & 0.59 \\
\hline cTnT-hs, ng/l & $7.8(6.1-9.7)$ & $7.9(6.1-9.9)$ & $6.5(5.6-8.2)$ & 0.07 & $7.2(6.0-9.0)$ & $10.6(9.6-11.9)$ & $<0.0001$ \\
\hline \multicolumn{8}{|l|}{ Hemostatic parameters } \\
\hline Fibrinogen, g/l & $3.2(2.4-3.9)$ & $3.2(2.4-3.9)$ & $3.3(2.5-4.5)$ & 0.45 & $3.2(2.5-3.9)$ & $3.0(2.4-4.1)$ & 0.37 \\
\hline D-dimer, ng/ml & $\begin{array}{c}369.5 \\
(240.8-515.3)\end{array}$ & $\begin{array}{c}361.0 \\
(240.0-512.3)\end{array}$ & $\begin{array}{c}386.0 \\
(246.5-734.5)\end{array}$ & 0.50 & $\begin{array}{c}374.0 \\
(244.5-514.5)\end{array}$ & $\begin{array}{c}337.0 \\
(237.0-550.0)\end{array}$ & 0.94 \\
\hline TAFI: Ag (\%) & $102.0(93.0-113.8)$ & $102.0(93.0-113.0)$ & $99.5(91.0-116.0)$ & 0.76 & $102.0(93.0-114.0)$ & $100.0(94.0-112.0)$ & 0.64 \\
\hline PAl-1: Ag, ng/ml & $27.4(8.4)$ & $27.5(8.5)$ & $26.6(7.5)$ & 0.66 & $27.2(8.4)$ & $29.0(8.3)$ & 0.29 \\
\hline $\mathrm{ETP}, \mathrm{nM} \times \min$ & $\begin{array}{c}1672.2 \\
(1510.9-1889.8)\end{array}$ & $\begin{array}{c}1672.2 \\
(1512.3-1878.3)\end{array}$ & $\begin{array}{c}1670.1 \\
(1495.3-2047.6)\end{array}$ & 0.76 & $\begin{array}{c}1670.0 \\
(1510.1-1873.0)\end{array}$ & $\begin{array}{c}1691.0 \\
(1543.5-2096.0)\end{array}$ & 0.36 \\
\hline $\mathrm{K}_{\mathrm{s}^{\prime}} \times 10^{-9} \mathrm{~cm}^{2}$ & $6.4(1.0)$ & $6.4(0.9)$ & $6.0(0.9)$ & 0.08 & $6.4(1.0)$ & $6.4(0.7)$ & 0.84 \\
\hline CLT, min & $105.0(21.4)$ & $104.8(21.5)$ & $107.5(20.4)$ & 0.61 & $102.9(20.5)$ & $117.0(22.7)$ & 0.001 \\
\hline
\end{tabular}

Data are presented as mean (SD) or median (IQR)

Abbreviations: Ag, antigen; CLT, clot lysis time; cTnT-hs, high-sensitivity cardiac troponin T; eGFR, estimated glomerular filtration rate; ETP, endogenous thrombin potential; GDF-15, growth differentiation factor-15; hs-CRP, high-sensitivity C-reactive protein; $\mathrm{K}_{\mathrm{s}^{\prime}}$ clot permeability; NT-proBNP, N-terminal pro-B-type natriuretic peptide; PAl-1, plasminogen activator inhibitor-1; TAFI, thrombin-activatable fibrinolysis inhibitor; other — see Table 1

Table 3. Cox regression analysis for clinical outcomes in patients with atrial fibrillation and stage 4 chronic kidney disease

\begin{tabular}{|c|c|c|c|c|}
\hline \multirow[b]{2}{*}{ Predictors of stroke, TIA, or systemic embolism } & \multicolumn{2}{|c|}{ Univariable analysis } & \multicolumn{2}{|c|}{ Multivariable analysis } \\
\hline & HR $(95 \% \mathrm{CI})$ & $P$-value & HR $(95 \% \mathrm{CI})$ & P-value \\
\hline Age, years & $1.10(1.01-1.19)$ & 0.02 & $1.11(1.02-1.20)$ & 0.01 \\
\hline $\mathrm{K}_{\mathrm{s}^{\prime}} \times 10^{-9} \mathrm{~cm}^{2}$ & $0.61(0.39-0.96)$ & 0.03 & $0.55(0.34-0.90)$ & 0.02 \\
\hline Predictors of major bleeding or CRNMB & HR $(95 \% \mathrm{Cl})$ & P-value & HR $(95 \% \mathrm{Cl})$ & P-value \\
\hline Cystatin C, mg/l & $2.70(0.92-7.90)$ & 0.07 & $9.24(2.15-39.67)$ & 0.003 \\
\hline cTnT-hs, ng/l & $1.24(1.13-1.36)$ & $<0.0001$ & $1.30(1.14-1.48)$ & 0.0001 \\
\hline GDF-15, per 100 pg/ml & $1.37(1.25-1.51)$ & $<0.0001$ & $1.48(1.29-1.69)$ & $<0.0001$ \\
\hline CLT, min & $1.03(1.01-1.05)$ & 0.001 & - & - \\
\hline Past bleeding & $5.76(2.32-14.33)$ & 0.0002 & $3.21(1.22-8.45)$ & 0.02 \\
\hline
\end{tabular}

Abbreviations: CRNMB, clinically relevant non-major bleeding; TIA, transient ischemic attack; other see Figure 1, Table 1, and Table 2

\section{Thromboembolism}

During the median follow-up at 25.5 (23.0-29.0) months, thromboembolic events occurred in $18(10 \%)$ patients (4.7\% per year). There were 16 (8.9\%) ischemic cerebrovascular events and $2(1.1 \%)$ systemic thromboembolic episodes. There were no differences in the variables studied in relation to these events (Table 1 and Table 2). However, in univariable and multivariable analyses, increased age and decreased $\mathrm{K}_{\mathrm{s}}$ were associated with thromboembolism (Table 3).

\section{Bleeding}

Twenty-seven (15\%) patients experienced bleeding (13 major and 14 clinically relevant non-major bleedings) while on anticoagulation (7.1\% per year). No differences in the variables studied were observed between the 27 subjects and the remaining participants except for the increased prevalence of prior major bleeding and less frequent beta-blocker use (Table 1). The patients with a history of major bleeding were over 8-fold more likely to develop gastrointestinal ( $n=12,3.2 \%$ per year) bleeding (HR, 8.29; $95 \% \mathrm{Cl}, 2.49-27.62 ; P=0.001)$ as compared to the others. Past bleeding, use of beta-blockers, increased GDF-15, cystatin C, and cTnT-hs were associated with major bleeds and CRNMB, along with prolonged CLT (Table 1 and Table 2), which, however, did not independently predict bleeding in contrast to previous bleeding and the three biomarkers (Table 3). The optimal cut-off points for the occurrence of bleeding estimated for, GDF-15, cTnT-hs and cystatin C were $1930.0 \mathrm{pg} / \mathrm{ml}$ (Youden index = 0.74; AUC, 0.885; 95\% $\mathrm{Cl}, 0.828-0.942 ; P<0.0001$ ), $9.3 \mathrm{ng} / \mathrm{l}$ (Youden index $=0.62$; AUC, $0.823 ; 95 \% \mathrm{Cl}, 0.747-0.899 ; P<0.0001)$ and $1.16 \mathrm{mg} / \mathrm{l}$ (Youden index $=0.48 ;$ AUC, $0.740 ; 95 \% \mathrm{Cl}, 0.657-0.823 ; P$ $<0.0001$ ), respectively (Supplementary material, Figure S1). 


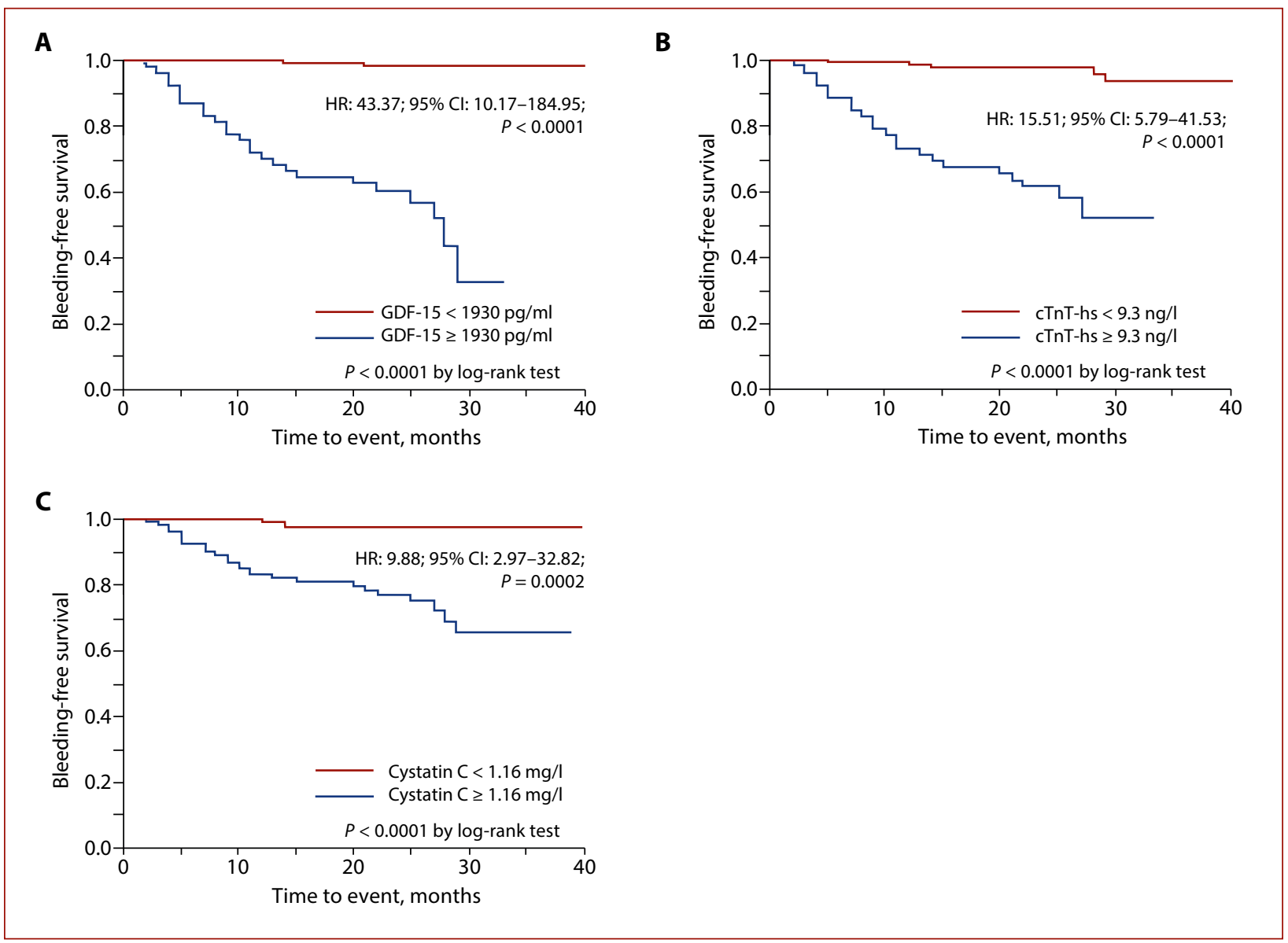

Figure 1. Association of growth differentiation factor-15 (A), high-sensitivity cardiac troponin T (B) and cystatin C (C) optimal cut-off points and the occurrence of clinically significant bleedings among patients with stage 4 chronic kidney disease and atrial fibrillation

Abbreviations: $\mathrm{Cl}$, confidence interval; cTnT-hs, high-sensitivity cardiac troponin T; GDF-15, growth differentiation factor-15; HR, hazard ratio

The Kaplan-Meier survival analysis showed that GDF-15, cTnT-hs, and cystatin C discriminated AF patients with stage 4 CKD at high risk of bleeding on anticoagulation, with the highest value observed for GDF-15 $\geq 1930 \mathrm{pg} / \mathrm{ml}$ (Figure 1).

\section{Mortality}

Twenty-five (13.9\%) patients died during the follow-up (6.5\% per year), including 9 (5.0\%) cardiovascular deaths. None of the four biomarkers and hemostatic parameters differed between non-survivors and survivors except for the fibrinogen concentration, which was slightly higher in the latter group. Mortality analysis is presented in Supplementary material, Table S1-S3. Regression analysis adjusted for age and comorbidities showed that solely cystatin $C$ was independently associated with poor survival (HR, 3.95; 95\% Cl, 1.08-14.37; $P=0.04$; Supplementary material, Table S3, Panel B).

\section{DISCUSSION}

In this cohort study, we have shown for the first time that in AF patients with stage 4 CKD, decreased fibrin clot permeability, indicating the formation of more compact fibrin networks, along with increased age, independently predict thromboembolic events that occur despite oral anticoagulation, while cystatin C, cTnT-hs, and GDF-15, together with past bleeding can independently predict clinically significant bleeding. Cystatin $C$ was identified as the only independent predictor of all-cause death. The current findings expand our knowledge on the prediction of adverse events by suggesting that in AF patients with stage 4 CKD, emerging biomarkers might help identify the patients, who require closer ambulatory surveillance and education, as well as those who might particularly benefit in terms of anticoagulation safety from the measurement of biomarkers, especially GDF-15.

\section{Biomarkers and prothrombotic state}

We provided evidence that concentrations of GDF-15 in these high-risk AF patients are positively associated with a key marker of thrombin generation measured in plasma, i.e. ETP, and a marker of impaired fibrinolysis, i.e. CLT, which extends previous findings [5]. Similar observations were made in AF patients with a median eGFR of $73.0 \mathrm{ml} / \mathrm{min} / 1.73 \mathrm{~m}^{2}$ [21]. There was no association between ETP and cardiac troponin I in patients with a median eGFR of $70.0 \mathrm{ml} / \mathrm{min} / 1.73 \mathrm{~m}^{2}$ [24]. The 3 biomarkers, which could be useful in risk stratification 
in AF patients and also acute pulmonary embolism [25], reflect, to some extent, the prothrombotic state typical of this arrhythmia, but their associations with other markers and prothrombotic state parameters at least in part seem to be diminished in severe CKD $[5,21,24,26]$.

\section{Prediction of TE}

Of importance, we found that low fibrin clot permeability, a key measure of fibrin clot density $[18,19]$, can predict TE outcomes in AF patients with stage 4 CKD, which extends our previous findings $[18,19]$ and highlights the role of fibrin properties in the pathophysiology of thromboembolism in AF. In contrast to $\mathrm{K}_{\mathrm{s}^{\prime}}$, we failed to observe a similar impact of hypolysability on this outcome, which suggests that changes in fibrin networks are more sensitive to most likely posttranslational modifications in severe CKD and in this subgroup have a stronger effect on the TE risk [20]. It might be speculated that therapies aimed at 'normalizing' fibrin clot structure might be useful in TE prevention [27].

\section{Prediction of bleeding}

We demonstrated that apart from prior major bleeding, cystatin C, GDF-15, and CTnT-hs can predict clinically relevant bleeding (not only major bleeds) also in AF patients with severe CKD, which supports previous observations on bleeding risk stratification [14, 28-30]. The 2020 European Society of Cardiology guidelines on the management of AF stated that biomarkers-based bleeding risk scores outperform clinical scores, for example, HAS-BLED, but there is insufficient evidence to implement them in practice [2]. Our study might suggest that in patients with low eGFR the predictive value of the novel biomarkers (but not eGFR assessed using the CKD-EPI formula) might be higher as compared to patients with better renal function, which warrants further studies.

\section{Prediction of death}

Our findings on a predictive role of cystatin C (but not eGFR assessed using the CKD-EPI formula) in terms of mortality in patients with AF and stage 4 CKD are novel. In line with our results, cystatin $C$ was shown - when included in eGFR calculation - to yield the highest $C$ index in terms of cardiovascular death prediction [31]. These data might be related to the fact that cystatin $C$ is a better marker of renal function than creatinine because it is constantly produced, freely filtrated, and less influenced by age and sex [31]. Moreover, cystatin C has been suggested to be more strongly associated with adverse clinical outcomes or states as compared to creatinine, beyond solely reflecting renal function [32]. Mechanisms underlying our observation linking cystatin C with mortality in stage 4 CKD remain to be elucidated.

\section{Limitations of the study}

The current cohort was relatively small. We measured biomarkers and hemostatic parameters only once. The assessment of proteinuria in the current study was based on the records from nephrologists. It is unclear whether mild proteinuria can impact the hemostatic variables assessed in this study. Our results might not be extrapolated to patients on dialysis.

\section{CONCLUSIONS}

In AF patients with stage 4 CKD while on anticoagulation, circulating biomarkers, apart from a history of major bleeding, have the highest clinical usefulness in the prediction of future bleeding events while low fibrin clot permeability, along with advanced age, may predict thromboembolic outcomes. The present study provides additional evidence that the current approach to risk stratification in AF patients with stage 4 CKD on oral anticoagulation may be suboptimal.

\section{Supplementary material}

Supplementary material is available at https://journals. viamedica.pl/kardiologia_polska.

\section{Article information}

Acknowledgments: This work was supported by a grant from Jagiellonian University Medical College (K/ZDS/007717, to A.U). P.T.M. was supported by the Ministry of Science and Higher Education stipend for outstanding young scientists.

Conflict of interest: AU received lecture honoraria from Bayer, Boehringer Ingelheim, and Pfizer, PTM received speech honorarium from Boehringer Ingelheim, while the rest of the authors declared no conflict of interest.

Open access: This article is available in open access under Creative Common Attribution-Non-Commercial-No Derivatives 4.0 International (CC BY-NC-ND 4.0) license, allowing to download articles and share them with others as long as they credit the authors and the publisher, but without permission to change them in any way or use them commercially. For commercial use, please contact the journal office at kardiologiapolska@ptkardio.pl.

How to cite: Matusik PT, Leśniak WJ, Heleniak Z, et al. Thromboembolism and bleeding in patients with atrial fibrillation and stage 4 chronic kidney disease: Impact of biomarkers. Kardiol Pol. 2021; 79(10): 1086-1092, doi: 10.33963/KP.a2021.0088.

\section{REFERENCES}

1. Benjamin EJ, Wolf PA, D'Agostino RB, et al. Impact of atrial fibrillation on the risk of death: the Framingham Heart Study. Circulation. 1998; 98(10): 946-952, doi: 10.1161/01.cir.98.10.946, indexed in Pubmed: 9737513.

2. Hindricks G, Potpara T, Dagres N, et al. ESC Scientific Document Group. 2020 ESC Guidelines for the diagnosis and management of atrial fibrillation developed in collaboration with the European Association for Cardio-Thoracic Surgery (EACTS): The Task Force for the diagnosis and management of atrial fibrillation of the European Society of Cardiology (ESC) Developed with the special contribution of the European Heart Rhythm Association (EHRA) of the ESC. Eur Heart J. 2021; 42(5): 373-498, doi: 10.1093/eurheartj/ehaa612, indexed in Pubmed: 32860505.

3. Bansal N, Xie D, Sha D, et al. Cardiovascular events after new-onset atrial fibrillation in adults with CKD: results from the Chronic Renal Insufficiency Cohort (CRIC) study. J Am Soc Nephrol. 2018; 29(12): 2859-2869, doi: 10.1681/ASN.2018050514, indexed in Pubmed: 30377231.

4. Potpara TS, Ferro CJ, Lip GYH. Use of oral anticoagulants in patients with atrial fibrillation and renal dysfunction. Nat Rev Nephrol. 2018; 14(5): 337-351, doi: 10.1038/nrneph.2018.19, indexed in Pubmed: 29578207.

5. Matusik PT, Heleniak Z, Papuga-Szela E, et al. Chronic kidney disease and its impact on a prothrombotic state in patients with atrial fibrillation. J 
Clin Med. 2020; 9(8):2476, doi: 10.3390/jcm9082476, indexed in Pubmed: 32752262.

6. Głowicki B, Matusik PT, Plens K, et al. Prothrombotic state in atrial fibrillation patients with one additional risk factor of the chads-vasc score (beyond sex). Can J Cardiol. 2019; 35(5): 634-643, doi: 10.1016/j. cjca.2019.01.014, indexed in Pubmed: 30955928.

7. Lodziński $P$, Gawałko M, Budnik M, et al. Trends in antithrombotic management of patients with atrial fibrillation. A report from the Polish part of the eurobservational research programme - atrial fibrillation general long-term registry. Pol Arch Intern Med. 2020; 130(3): 196-205, doi: 10.20452/pamw.15157, indexed in Pubmed: 31976927.

8. Sorigue M. Oral anticoagulation in patients with active cancer and atrial fibrillation: current challenges. Pol Arch Intern Med. 2020; 130(10): 878-886, doi: 10.20452/pamw.15315, indexed in Pubmed: 32329983.

9. Steffel J, Verhamme P, Potpara TS, et al. ESC Scientific Document Group. The 2018 European Heart Rhythm Association Practical Guide on the use of non-vitamin $\mathrm{K}$ antagonist oral anticoagulants in patients with atrial fibrillation. Eur Heart J. 2018; 39(16): 1330-1393, doi: 10.1093/eurheartj/ehy136, indexed in Pubmed: 29562325.

10. HeleniakZ, Papuga-Szela E, Plens K, et al. Efficacy and safety of non-vitamin $k$ antagonist oral anticoagulants in patients with atrial fibrillation and chronic kidney disease stage G4: a single-center experience. J Cardiovasc Pharmacol. 2020; 76(6): 671-677, doi: 10.1097/FJC.0000000000000911, indexed in Pubmed: 33284572.

11. Janion-Sadowska A, Sadowski M, Konieczyńska M, et al. Polish regional differences in patient knowledge on atrial fibrillation and its management as well as in patterns of oral anticoagulant prescription. Kardiol Pol. 2019; 77(4):437-444, doi: 10.5603/KP.a2019.0036, indexed in Pubmed: 30835335.

12. Hijazi Z, Lindbäck J, Alexander JH, et al. ARISTOTLE and STABILITY Investigators. The $A B C$ (age, biomarkers, clinical history) stroke risk score: a biomarker-based risk score for predicting stroke in atrial fibrillation. Eur Heart J.2016;37(20): 1582-1590, doi: 10.1093/eurheartj/ehw054, indexed in Pubmed: 26920728.

13. Oldgren J, Hijazi Z, Lindbäck J, et al. Performance and validation of a novel biomarker-based stroke risk score for atrial fibrillation. Circulation. 2016; 134(22): 1697-1707, doi: 10.1161/circulationaha.116.022802, indexed in Pubmed: 27569438.

14. Matusik PT. Biomarkers and cardiovascular risk stratification. Eur Heart J. 2019; 40(19): 1483-1485, doi: 10.1093/eurheartj/ehz265, indexed in Pubmed: 31087049.

15. Wang Y, Li W, Yang J, et al. Association between cystatin $C$ and the risk of ischemic stroke: a systematic review and meta-analysis. J Mol Neurosci. 2019; 69(3): 444-449, doi: 10.1007/s12031-019-01373-1, indexed in Pubmed: 31313057.

16. Martens RJH, Kimenai DM, Kooman JP, et al. Estimated glomerular filtration rate and albuminuria are associated with biomarkers of cardiac injury in a population-based cohort study: the Maastricht study. Clin Chem. 2017; 63(4): 887-897, doi: 10.1373/clinchem.2016.266031, indexed in Pubmed: 28213568.

17. Ezekowitz MD, Connolly S, Parekh A, et al. Rationale and design of RE-LY: randomized evaluation of long-term anticoagulant therapy, warfarin, compared with dabigatran. Am Heart J. 2009; 157(5): 805-810.e2, doi: 10.1016/j.ahj.2009.02.005, indexed in Pubmed: 19376304.

18. Janion-Sadowska A, Chrapek M, Konieczyńska M, et al. Altered fibrin clot properties predict stroke and bleedings in patients with atrial fibrillation on rivaroxaban. Stroke. 2018 [Epub ahead of print]: STROKEAHA118023712, doi: 10.1161/STROKEAHA.118.023712, indexed in Pubmed: 30580709.
19. Drabik $L$, Wołkow $P$, Undas A. Fibrin clot permeability as a predictor of stroke and bleeding in anticoagulated patients with atrial fibrillation. Stroke. 2017; 48(10): 2716-2722, doi: 10.1161/STROKEAHA.117.018143, indexed in Pubmed: 28904234.

20. Drabik L, Konieczyńska M, Undas A. Clot lysis time predicts stroke during anticoagulant therapy in patients with atrial fibrillation. Can J Cardiol. 2020;36(1): 119-126, doi: 10.1016/j.jca.2019.08.001, indexed in Pubmed: 31740169.

21. Matusik PT, Małecka B, Lelakowski J, et al. Association of NT-proBNP and GDF-15 with markers of a prothrombotic state in patients with atrial fibrillation off anticoagulation. Clin Res Cardiol. 2020; 109(4): 426-434, doi: 10.1007/s00392-019-01522-x, indexed in Pubmed: 31280356.

22. Schulman $\mathrm{S}$, Angerås $\mathrm{U}$, Bergqvist $\mathrm{D}$, et al. Subcommittee on Control of Anticoagulation of the Scientific and Standardization Committee of the International Society on Thrombosis and Haemostasis. Definition of major bleeding in clinical investigations of antihemostatic medicinal products in surgical patients. J Thromb Haemost. 2010; 8(1): 202-204, doi: 10.1111/j.1538-7836.2009.03678.x, indexed in Pubmed: 19878532.

23. Kaatz S, Ahmad D, Spyropoulos AC, et al. Subcommittee on Control of Anticoagulation. Definition of clinically relevant non-major bleeding in studies of anticoagulants in atrial fibrillation and venous thromboembolic disease in non-surgical patients: communication from the SSC of the ISTH. J Thromb Haemost. 2015; 13(11): 2119-2126, doi: 10.1111/jth.13140, indexed in Pubmed: 26764429.

24. Matusik PT, Prior SM, Butenas S, et al. Association of cardiac troponin I with prothrombotic alterations in atrial fibrillation. Kardiol Pol. 2018; 76(7): 1106-1109, doi: 10.5603/KP.2018.0134, indexed in Pubmed: 29984810.

25. Ząbczyk M, Natorska J, Janion-Sadowska A, et al. Prothrombotic fibrin clot properties associated with NETs formation characterize acute pulmonary embolism patients with higher mortality risk. Sci Rep. 2020; 10(1): 11433, doi: 10.1038/s41598-020-68375-7, indexed in Pubmed: 32651425.

26. Matusik PT, Matusik PS, Kornacewicz-Jach Z, et al. Elevated NT-proBNP is associated with unfavorably altered plasma fibrin clot properties in atrial fibrillation. Int J Cardiol. 2017; 243: 244-250, doi: 10.1016/j. ijcard.2017.05.060, indexed in Pubmed: 28571619.

27. Bridge Kl, Philippou H, Ariëns RAS. Clot properties and cardiovascular disease. Thromb Haemost. 2014; 112(5): 901-908, doi: 10.1160/TH14-020184, indexed in Pubmed: 24899357.

28. Hijazi Z, Oldgren J, Lindbäck J, et al. ARISTOTLE and RE-LY Investigators. The novel biomarker-based ABC (age, biomarkers, clinical history)-bleeding risk score for patients with atrial fibrillation: a derivation and validation study. Lancet. 2016; 387(10035): 2302-2311, doi: 10.1016/S0140-6736(16)00741-8, indexed in Pubmed: 27056738.

29. DrabikL, Matusik PT, Undas A. The ORBIT bleeding score is associated with lysis and permeability of fibrin clots. Kardiol Pol. 2019; 77(12): 1182-1185, doi: 10.33963/KP.15020, indexed in Pubmed: 31607742.

30. Undas A, Drabik L, Potpara T. Bleeding in anticoagulated patients with atrial fibrillation: practical considerations. Kardiol Pol. 2020; 78(2): 105-116, doi: 10.33963/kp.15205, indexed in Pubmed: 32108755.

31. Hijazi Z, Granger CB, Hohnloser $\mathrm{SH}$, et al. Association of Different Estimates of Renal Function With Cardiovascular Mortality and Bleeding in Atrial Fibrillation. J Am Heart Assoc. 2020; 9(18): e017155, doi: 10.1161/JAHA.120.017155, indexed in Pubmed: 32865097.

32. Hijazi Z, Oldgren J, Siegbahn A, et al. Application of biomarkers for risk stratification in patients with atrial fibrillation. Clin Chem. 2017; 63(1): 152-164, doi: 10.1373/clinchem.2016.255182, indexed in Pubmed: 27811208. 